This is the accepted manuscript of an article published in the Journal of Cancer Survivorship in July 2015. Doi: 10.1007/s11764-015-0466-7

\title{
Title page: Dismantling the Present and Future Threats of Testicular Cancer: a Grounded Theory of Positive and Negative Adjustment Trajectories
}

Lauren Matheson ${ }^{1}$, Mary Boulton ${ }^{1}$, Verna Lavender ${ }^{1}$, Andrew Protheroe ${ }^{2}$, Sue Brand ${ }^{3}$, Marta Wanat ${ }^{1}$ and Eila Watson ${ }^{1}$

${ }^{1}$ Cancer Care Research Group, Department of Clinical Health Care, Faculty of Health and Life Sciences, Marston, Oxford Brookes University, Oxford, OX3 0FL

${ }^{2}$ University of Oxford Department of Oncology, Oxford Cancer and Haematology Centre, Oxford University Hospitals Trust, Headington, Oxford, OX3 7LJ

${ }^{3}$ Bristol Testicular Cancer service, Bristol Haematology and Oncology centre, University Hospitals Bristol, Horfield Road, Bristol, BS2 8ED

Corresponding author: lauren.matheson-2011@brookes.ac.uk Telephone: 01865482785 


\section{Abstract}

Purpose: Testicular cancer commonly affects men in the prime of their lives. While survival rates are excellent, little previous research has examined men's experiences of adjustment to survivorship. We aimed to explore this issue in younger testicular cancer survivors.

Methods: In-depth qualitative interviews were conducted with testicular cancer survivors over two time points approximately 6 months apart in the year following treatment completion. Interviews were analysed using a Grounded Theory approach.

Results: The sample included 18 testicular cancer survivors between $22-44$ years (mean age 34). A Grounded Theory was developed, which explained the process of positive adjustment over the first year following treatment completion in terms of men's ability to dismantle the present and future threats of cancer, involving the key transitions of gaining a sense of perspective and striving to get on with life and restore normality. These were facilitated by six key processes. The processes that explained a negative adjustment trajectory are also presented.

Conclusions: These findings contribute to the understanding of the psychosocial impact of testicular cancer on younger men's lives and have implications for the provision of support to testicular cancer survivors. Further investigation into the feasibility of one-onone peer support interventions is warranted, as well as informal support that respects men's desire for independence.

Implications for cancer survivors: Understanding the processes involved in adjustment highlights ways in which health professionals can offer support to those struggling to adjust through challenging illness beliefs, encouraging emotional disclosure and facilitating peer mentoring. 
Key words: Testicular cancer, adjustment, cancer survivorship, qualitative, grounded theory

\section{Introduction}

Testicular cancer most commonly develops in younger men aged 15 to 40 years [1]. Approximately 2,200 men in the UK are diagnosed with the disease each year, with men under 35 years accounting for around $50 \%$ of all cases [2]. Across the developed world, it is predicted that there will be nearly $25 \%$ more cases by 2025 , indicating that this is a growing problem $[1,3]$. Due to advances in treatment, testicular cancer has the highest survival rates for any UK cancer, as $98.2 \%$ of men will survive for at least 10 years after diagnosis [4]. Treatment regimens may, however, increase men's risk of future cardiovascular toxicity, secondary cancers and infertility [5].

Compared to other cancer sites, there is a notable paucity of research exploring the psychosocial issues in testicular cancer survivors $[6,7]$ with few studies conducted in the UK [8-11]. Previous quantitative research suggests that testicular cancer survivors report levels of quality of life comparable to healthy men [12-14]. However, generic measures of quality of life may not be sufficient to capture difficulties specific to this population and specific testicular cancer quality of life measures recently developed have not yet been utilised $[15,16]$. Although studies are scarce, there is evidence that a significant minority of testicular cancer survivors may be at risk of anxiety, sexual dysfunction, infertility and body image concerns [6, 17-20]. Similar to other cancer survivors [21], a significant proportion of testicular cancer survivors report unmet needs regarding dealing with fear of recurrence, relationships, finances and body image, often associated with poorer quality of life and distress [22, 23]. Young men under 30 years old with testicular cancer are a particularly vulnerable group, at greater risk of anxiety and suicide compared 
to healthy men $[19,24]$. A diagnosis may be a shocking and distressing experience for men, who are often in the prime of their lives $[25,26]$. However, younger men's experiences and needs have not been extensively explored [27]. This is particularly the case in relation to men's experiences of moving from active treatment to a follow-up regimen, identified as a difficult transition for survivors of other cancers [28]. To date, few studies have used a qualitative approach and most of those that have done so have examined specific issues, such as views towards testicular prosthetic implants, rather than taking a holistic approach to understanding men's experiences $[26,29,9,30,11,31,25$, 32]. In the UK, finding ways of promoting recovery is a key priority outlined by the National Cancer Survivorship Initiative (NCSI) [33] and further qualitative studies are needed to inform the development of appropriate interventions.

This study aimed to provide an in-depth exploration of the experiences of younger testicular cancer survivors regarding adjustment following treatment completion, and to develop a grounded theory which could inform service provision and intervention development.

\section{Sample and Methods}

\section{Study design}

A longitudinal qualitative design was chosen in order to explore participants' experiences of adapting to cancer over an extended period following treatment [34]. A qualitative study was deemed appropriate due to the lack of previous in-depth research on the experiences of testicular cancer survivors. It was decided to conduct interviews with patients at two time points six months apart as this initial transition period following treatment completion has been shown to be a time when survivors exhibit changing unmet needs [28] and a six month gap was feasible within the time period of the study. 


\section{Ethics}

Ethical approval was obtained from Oxford Brookes University and the South Central Oxford C National Health Service (NHS) research ethics committee (REC reference 12/SC/0215).

\section{Recruitment}

Patients were eligible to participate in the study if they had been diagnosed with testicular cancer, were between 20-45 years old, had been treated with curative intent and had completed initial or secondary treatment within the previous six months. The National Cancer Institute (2013) define young adulthood as extending up to 39 years of age [35] but this was regarded as too restrictive in relation to the aims of this study given contemporary patterns of partnering, child bearing and employment.

Patients were recruited from three NHS hospitals in the South of England. Eligible patients were identified by their clinician or clinical nurse specialist (CNS) during an appointment around the time of treatment completion and were offered an information pack containing an information sheet, response form and return envelope. Potential participants were asked to respond via post, email, phone or text to the research team if they were interested in participating.

\section{Data collection}

Semi-structured face-to-face interviews with patients were conducted by LM within six months of treatment completion (Time 1) and approximately 6 months later (Time 2) from 2012 to 2014. Interviews at Time 1 took place in participants' homes $(n=14)$, workplace $(n=1)$, or in a public café $(n=3)$, according to the preference of the participant, while those at Time 2 were conducted in participants' homes $(n=13)$ or workplace $(n=1)$. A semi-structured interview guide was used, which was developed by the research team, with input from cancer survivor representatives $(n=2)$, a urology clinician (AP) as well as 
current research. Patients were asked open-ended questions about their experiences regarding the psychosocial impact of cancer on different aspects of their lives, their information and support needs and suggestions for improvements to services. Interviews were digitally recorded, fully transcribed and anonymised. Patients also completed a brief demographic questionnaire.

Around 6 months after the Time 1 interview, participants were contacted to arrange a second interview. At Time 2, the interview schedule included key questions from the initial interviews as well as new questions that were added to explore key questions emerging from the grounded theory. Furthermore, at Time 2, any individual issues that arose from Time 1 were followed up for each participant. On average, interviews lasted 70 minutes at Time 1 and 50 minutes at Time 2.

\section{Data analysis}

Interviews were analysed by LM using Grounded Theory, following Charmaz's [36] social constructivist approach. Firstly, line-by-line codes were assigned systematically to the transcript, followed by focused coding, which involved the use of more analytical codes [36]. The data were then sorted and organised into categories and sub-categories. A constant comparison approach was used iteratively throughout. Finally, theoretical coding was employed, whereby overarching categories were constructed. Data analysis began after the first interview and continued throughout the period of data collection [36], so theoretical hypotheses were developed and tested throughout. All Time 1 interviews were analysed individually before Time 2 interviews took place, so that any issues could be followed up at Time 2 . Time 2 interviews were initially examined individually and then collectively with those from Time 1 to explore similarities and differences over time. As the analysis progressed, it was evident that for many participants, there was little evidence of change over time. Most participants continued on a positive trajectory, 
although a few experienced increasing distress and negative adjustment. The key processes identified in the grounded theory were also consistent across time. For those who showed little evidence of change, Time 2 interviews provided further depth to the data collected at Time 1 and richer insights into the development of the themes over time. A grounded theory was developed for the interview data as a whole. Data collection ceased when data sufficiency [37] was achieved, as no new major categories were evident.

LM kept a reflexive research diary [38] and wrote detailed memos [36] to explore and develop the emerging categories and theory. In order to maximise reliability, EW and MB independently listened to six interviews, MW independently analysed a section of a transcript and the research group all commented on the developing analysis. The concepts were discussed with the clinical authors (SB, AP).

\section{Results}

A total of 54 men were offered information packs. Four (7\%) refused to take a pack, 32 (59\%) took a pack but failed to respond and 18 (33\%) agreed to participate in the study. Participants were between 22-44 years old, with a mean age of 34. Participants demographic and treatment data is summarised in Table 1. At Time 1, all had completed initial treatment, with two participants recently completed treatment for a recurrence. One participant underwent treatment for a recurrence between interviews. Most (15/18) were invited for Time 2 interview and 14 participants accepted the invitation. Three participants were not invited for Time 2 interview as data saturation had been achieved. Time 2 interviews were completed on average 7 months after Time 1 (range 6-9 months). Overall, 32 interviews were conducted with participants during the first year following treatment completion. 


\section{Grounded Theory: Dismantling the Present and Future Threats of Testicular Cancer}

A grounded theory is presented that aims to explain the processes involved in positive adjustment to testicular cancer and highlight what led a few men to struggle to adjust in the year following treatment (see Figure 1). Testicular cancer was initially a shocking and disruptive experience, which posed threats to men's assumptions about their health, sense of normality, relationships, body and future. Adjustment was conceptualised as a dynamic and cyclical process of dismantling the threats of cancer and involved two key transitions, each involving three processes. The first key transition of gaining a sense of perspective over the threats of testicular cancer, involved an appraisal or sense-making process, as men sought to resolve the discrepancies between their prior assumptions towards testicular cancer and the actual experience. Firstly, men actively engaged in the process of minimisation of the significance of testicular cancer, which was often perceived as a relatively minor event. Reflecting on positive meaning derived from having cancer led men to gain a greater sense of illness coherence [39] over the event, often noted for its surrealism and brevity. Following this, men engaged in a process of positive reframing in order to further dismantle the threats of testicular cancer, through holding onto positive illness beliefs and making social comparisons, and strongly defending these perceptions against societal misconceptions towards cancer. Taking an active approach to overcoming the threats involved the utilisation of external resources and informal one-to-one peer support, especially with other testicular cancer survivors. Collectively, these three processes enabled participants to gain a sense of perspective over the threats of testicular cancer, particularly to dismantling the threats posed by diagnosis and treatment.

The second key transition, striving to get on with life and restore normality involved the dismantling of threats to the future, enabling men to feel that the disease was largely a 
'closed chapter'. Firstly, this involved the active process of acceptance and normalisation of the threats, particularly to the loss of a testicle and concerns about visible appearance. In addition, preserving and enhancing the normal self was important in defending against the threat to men's identities and of illness centrality, as the idea of having a cancer survivor identity was strongly rejected by participants. This helped men maintain their normal identities throughout the experience, aided by the resumption of fitness regimens and work or social roles. Furthermore, some men constructed an enhanced sense of selfidentity, which helped maintain a sense of control. Finally, re-establishing or holding onto anchors of security and actively choosing to relinquish fears, such as the threat to future fatherhood or fear of recurrence, also helped to dismantle the future threat, helping men get on with life.

Collectively, these processes led to a sense of acceptance, coherence, normality and security over the threats of cancer, which were dimensions of positive adjustment, often achieved by Time 1 interview. Conversely, opposing strategies to the ones described, could lead to negative adjustment in a few men. In particular, taking a generalised view of cancer and holding negative illness perceptions, maintaining a stoical and 'silent' coping style, ambivalent acceptance of the threats and a struggle to relinquish fears could lead to ongoing negative adjustment, manifesting in greater insecurity, isolation, fear and a disrupted self-identity. Contextual influences, particularly men's relationship and fatherhood status, influenced the magnitude of cancer threats, as single or childless men appraised the threats as more significant, and actively strove to regain control over them. Those who had already achieved key developmental milestones felt more secure from the threats. 


\section{Key Transition 1: Gaining a sense of perspective over the threats of testicular cancer}

\section{Process 1. Minimising the significance of testicular cancer - resolving the mismatch between assumptions and experience}

Men engaged in a process of weighing up the significance of testicular cancer, often appraising it as a minor disruptive event in their lives ('it's not that big a deal...I don't think it's been bad at all' P16, T1, 38 yrs, Married, Surgery+C), contrary to their initial assumptions and fears. Transitioning from an initial state of shock and fear involved relinquishing assumptions and cultural connotations about cancer and resolving the mismatch between these assumptions and their experience of testicular cancer, often felt to be not as bad as expected, especially if only minimal treatment was required.

'I just felt like I had an operation, it didn't feel what everybody tells you what cancer's like' (P2, T2, 24 yrs, Single, Surgery+C*)

Appraisals of testicular cancer as a relatively minor biographical event helped men to gain a sense of perspective, thus dismantling the threat to men's biographies, identities and sense of normality.

'It has had an effect, it's just one of these things that you can either sit there and mope about it or you can just accept it, and then weigh it all up and realise that actually, it's not that bad, it could be a lot worse, so you've been pretty lucky, look on the brighter side as opposed to dwelling on the bad, ..I think it's been ok' (P23, $\mathrm{T} 1,30 \mathrm{yrs}$, In a relationship, Surgery+C)

Minimisation of cancer increased men's feelings of mastery over the disease, and some even reframed the disease as one of life's challenges to overcome. Men's appraisals 
towards the threat of cancer appeared more important than their actual treatment or disease status.

'It was just an obstacle I had to get around, it was never, never anything that was going to shut me down or stop, so I didn't see it, I don't see it as a major thing' (P20, T1, 22 yrs, Single, Surgery+C**)

If men struggled to resolve the discrepancy between assumptions and experience, a sense of ambivalence over the disease experience could result, which contributed to negative adjustment. Perceptions of the significance of testicular cancer were influenced by fatherhood status, as men who wanted to start a family or have more children perceived it as more disruptive to their plans and assumptions. These men, as well as men who were single, derived and held more strongly to positive gains from the experience. For instance, testicular cancer could have a positive transformative effect, particularly to men's outlook ('wake-up call' P17, T1, 27 yrs, Single, Surgery+C), as they reported strengthened relationships and sense of meaning. Holding onto these positive gains helped men to gain a sense of coherence over the event, including a sense that the experience was meaningful.

'almost the benefit of having cancer it makes you re-evaluate your whole life and your friendships and the way you are and your job, cos before that you just tick along....so sometimes a boot up the backside' (P18, T1, 44 yrs, Single, Surgery $+\mathrm{R}+\mathrm{C}$ ) 


\section{Process 2. Positive reframing of the threat of testicular cancer - Making}

social comparisons and holding onto positive illness perceptions

The process of making meaningful social and intrapersonal comparisons helped men reframe testicular cancer in a less threatening way. For instance, downward social comparisons to those worse off helped to dismantle the threat to their current lives.

'If I was on my own and I didn't have kids and a wife I might have thought differently about the treatment and what it's done to me, but because I've got a wife and kids I'm all settled down, that side of things didn't really worry me it's more of how they were gonna feel' (P5, T1, 28 yrs, Married, Surgery+C)

Men also used upward social comparisons to those better off, such as those in remission or coping well, including other testicular cancer patient 'role models', which reduced the threat to their future lives. In addition, comparisons with similar others helped normalise current feelings or symptoms. Furthermore, the process of holding onto positive illness perceptions and embracing the positive discourse surrounding the disease helped to dismantle the threat to psychological wellbeing. Perceptions were shaped by health professionals reassuring men that testicular cancer was 'the best one to get' ( $\mathrm{P} 7, \mathrm{~T} 1,43$ yrs, In a relationship, Surgery+C). Specifically, positive perceptions of the disease as highly curable, requiring relatively quick and less intensive treatment were maintained by participants. Importantly, perceiving testicular cancer as a distinct or specific disease helped to compartmentalise the threat.

'Testicular cancer is not really cancer, it's like baby cancer' (P17, T1, 27 yrs, Single, Surgery+C)

Men actively defended these positive perceptions, which could be threatened by what was felt to be distorted and stigmatising societal views of cancer in others ( it does have a 
stigma against it' P15, T1, 40 yrs, Married, Surgery). In contrast, a generalised view of cancer was taken by men who were not able to positively reframe the threat, which characterised negative adjustment. This in turn increased feelings of susceptibility to the threat of recurrence, evident by Time 2 interview in one participant ('No matter how good the outcomes are, you still had cancer' P10, T2, 41 yrs, Married, Surgery). Perceptions of testicular cancer as an enduring threat, as opposed to a transient one, also contributed to negative perceptions, as the passing of time was seen as the only way of reducing this threat.

\section{Process 3. Taking an active approach to overcoming the threats - utilising} external resources and 'informal' one-on-one peer support

Men felt that testicular cancer was often more distressing for their spouse and close family, so they initially emphasised the importance of 'staying strong' for others. However over time, most men seemed to adopt more active approaches to overcoming the perceived threats of cancer, through utilising external resources and becoming more flexible in their adherence to 'traditional' masculine values. Looking across the sample, men who adopted this coping style of active support seeking and emotional disclosure fared better by Time 2 than those who continued to be stoical and silent, who concealed their feelings and concerns from partners/family members and health professionals. Most men seemed to highly value having opportunities to reflect, including during the research interview. This helped them gain a sense of perspective and feel supported in their relationships, as talking about cancer in an everyday setting sometimes needed to be sanctioned by others.

However, negative adjustment was influenced by a more rigid adherence to 'traditional' masculine values, which led to the maintenance of a false positive front ('there's a kind of pressure to say, yeah, you're fine' $\mathrm{P} 10, \mathrm{~T} 2,41 \mathrm{yrs}$, Married, Surgery). In a minority of 
men, this could come at the cost of feeling unsupported and isolated by Time 2 , as it constricted men's willingness to seek support. In addition, some reported peers who provided inadequate support or even abandoned the friendship, which could further hinder men's attempts to seek out solidarity from 'normal' peers. Humour was often used during social situations to diffuse embarrassment of others, defend against the stigma of cancer and the threat to a 'normal' self.

Men strongly valued one-on-one informal peer support, particularly from other men with testicular cancer ('you can't bottle it all up' P23, T1, 30 yrs, In a relationship, Surgery+C). While men valued receiving peer support, they were particularly keen on giving peer support and often had a strong desire to share 'expert' knowledge of testicular cancer. Peer support helped to normalise the experience, reduce men's initial treatment concerns and shape realistic perceptions of testicular cancer.

'I just think it just helped just reassure me, like I wasn't a nutter, or some weirdo, and you're not the only person, you won't ever be the only person who's gone through it' (P20, T1, 22 yrs, Single, Surgery+C)

Following treatment, peer support helped men better accept a state of 'new normal'. Men who did not receive peer support felt it would have helped them dismantle their fears earlier, particularly towards a threatened masculinity, psychological wellbeing and work life ('that would have been nice to have had a mentor' P18, T2, 44 yrs, Single, Surgery $+\mathrm{C}+\mathrm{R})$. Participants emphasised the need for connections with cancer peers that were informal and offered to them as part of their care, as having to seek out support could challenge their masculinity ('probably men will go down the pub won't they?' 1 , T1, 36yrs, Married, Surgery+R*). Most felt professional psychological support was not needed, and the few that did, felt it would be better accepted if part of the care package, or even suggested by a peer mentor to normalise help-seeking. Despite their efforts, men 
often expressed frustration over the lack of experiential information congruent with their own experience, and desired more positive and realistic information on testicular cancer given earlier on.

\section{Key Transition 2: Striving to get on with life and restore normality}

\section{Process 4: Accepting and normalising the threats - accepting a new body}

\section{normality and the timing of cancer in younger adulthood}

The process of active acceptance and normalisation of the threats to body image contributed to this transition to normality. Almost all men perceived the loss of a testicle as a relatively insignificant loss, in comparison to the threat of death ('I'd rather have one [testicle] and be here!' P12, T2, 37 yrs, In a relationship, Surgery). Participants perceived similarities in terms of the function, aesthetics and their feelings towards the new 'normal' body after testicular cancer ('I don't feel any different now' P7, T2, 43 yrs, In a relationship, Surgery+C). Men also challenged cultural assumptions around the body, asserting that the presence of a complete set of testicles was not an important part of being male, and emphasised other aspects of masculinity which were more valued, such as fatherhood, marriage or careers.

'It doesn't make me any less of a bloke than the bloke next door; it doesn't really change me at all' (P16, T1, 38 yrs, Married, Surgery+C)

This transition from fear to acceptance regarding the loss of a testicle was often a quick process, with some men admitting initial threatened feelings that had improved over time. Men who had already achieved key developmental milestones, such as fatherhood and marriage, had a greater sense of security in their body that tempered the threat to masculinity ('you don't necessarily feel you have anything to prove' $\mathrm{P} 9, \mathrm{~T} 2,44 \mathrm{yrs,}$ Married, Surgery+C). For these reasons, only two men opted for a prosthetic testicle. 
However, some single men attempted to compensate for the loss of a testicle by testing their physical fitness, while other single men reframed their altered body as a change that had enhanced their unique identity and was a symbol of their pride in surviving cancer.

'I've got a few battle wounds to talk about now instead of nothing' (P20, T1, 22 yrs, Single, Surgery+C**)

While the majority of men did not perceive any ongoing issues, a few men encountered ongoing difficulties with fatigue (sometimes despite being treated by surgery alone), so had to re-adjust their expectations over the timing of their recovery to accept this change to normality by Time 2 . Knowing what to expect seemed important for men to feel in control and so refocus on striving towards normality. While some expressed frustration over a lack of explanation for their fatigue, wanting more advice on their expected recovery trajectory and how to manage fatigue better, they were often reluctant to ask their clinician. Some were unsure whether they should be asking their hospital specialist or GP for advice, feeling stuck between primary and secondary care.

'You just want someone to go, if you've got a problem go to your GP, or if not you phone this person, any questions phone this person, that would be the only thing, [health professionals'] just kind of go 'well you're fine you're fine' (P10, T1, 41 yrs, Married, Surgery)

In order to regain a sense of normality and get on with their lives, most men sought to accept and reframe the experience of having testicular cancer. For example, the onset of cancer in younger adulthood could be perceived in positive terms when it was seen as prompting them to initiate changes to their lives at an earlier stage than would otherwise have been the case. However, some men, particularly those who were treated with 
surgery alone and so experienced no symptoms or side effects, were more ambivalent in their acceptance that they had testicular cancer.

'I don't know whether I've fully accepted it, even though I'm completely treatment free and I've gone through it and I've beaten it, as it were, I suppose I'm still waiting for it to really sink in, that oh I had that and now it's gone, and that I ever had it at all..' (P2, T1, 24 yrs, Single, Surgery)

At Time 2, a minority of men had experienced periods of stress and feeling 'low' following returning to work, especially in those with financial pressures, yet sought to find a sense of balance in their lives through normalising and accepting their feelings and disclosing their concerns to others.

'some days you feel absolutely fine and silly little things remind you that you actually had cancer.... for a while I felt low and yeah I admit to my wife I'd thought at some stages I was maybe suffering from depression...I felt not lonely, sort of very pressurised and was very snappy, and then all of a sudden out the blue you have a good week, two weeks and things are fine, but things easily build, got on top of me very quickly, so I'd come back down again, no I never went to the doctors or anything, from time to time I still do get these times, but I'm assume that's life of living with cancer, and a young family and pressures of life' (P1, T2, 36 yrs, Married, Surgery+R*)

\section{Process 5. Preserving and enhancing the normal self - defending against}

\section{illness centrality and constructing an enhanced sense of personhood}

Although men's identities could be threatened by cancer, they were not often disrupted, as men sought to preserve and enhance the normal self, particularly through regaining 
their work and social roles. Some men strongly defended against 'illness centrality', rejecting the idea that a cancer survivor identity was integral to their sense of self.

'It's just one part of thousands of one of the things that happen in your life.. I don't see it as a defining part of me' (P9, T1, 44 yrs, Married, Surgery+C)

While some rejected common societal notions of cancer survivorship, including expectations regarding involvement in charities, a few others enhanced their identities through their charity involvement. In addition, others re-negotiated their identities, often through becoming less work and more family-orientated, exhibiting greater confidence in breaking out of 'traditional' gender roles. However, younger men expressed frustrations over the disruption to their careers, at least temporarily. Furthermore, some men, especially single or childless men, engaged in strategies to enhance their sense of personhood, which helped maintain a sense of control. For instance, men discussed having a strong sense of personal growth through feeling more unique from their peer group and reported greater self-confidence.

However, for some, identity could be threatened by changes to visible appearance such as weight gain or alopecia, due to chemotherapy or radiotherapy treatment, which were perceived as more threatening to their identity and confidence than losing a testicle (' $y o u$ kind of lose a little bit of your identity' P2, T2, $24 \mathrm{yrs,} \mathrm{Single,} \mathrm{Surgery+C*).} \mathrm{Yet} \mathrm{this}$ threat was often transient, and subsided as treatment-related side effects wore off. During this time men sought to preserve their identity through using humour over appearance, protect their children from concerns and regain their physical health normality through exercise goal setting. However, one participant encountered identity disruption by Time 2 as he struggled to maintain a 'normal' identity, which culminated in lower self-efficacy in his home and social roles and a sense of inadequacy. This was influenced by a sense of helplessness over where to get support for ongoing issues. 
'I don't at times feel good about myself, and then that worries me that I'm perhaps not as good as I should be for my wife and my child and everything else, and it does bother me.. but there doesn't seem to be an avenue you can go, to sort it' (P10, T2, 41 yrs, Married, Surgery)

\section{Process 6. Re-establishing a sense of security and letting go of fears -}

\section{Holding onto anchors of security}

The process of learning to relinquish fears over the future, particularly in relation to cancer recurrence, and re-establish or maintain a sense of security enabled men to get on with life. Through actively choosing not to ' $d$ well on it' (P18, T2, 44 yrs, Single, Surgery $+\mathrm{C}+\mathrm{R}$ ) as well as boxing away the experience, men strove to let go of any perceived threats towards their future lives. Overall, a pragmatic attitude towards the threat of recurrence was taken ('if it happens, it happens' P15, T1, 40 yrs, Married, Surgery).

'It's something now I don't even think about...it's done and dusted' (P7, T2, 43 yrs, In a Relationship, Surgery+C)

Accepting the precarious nature of life and attempting to live with greater intentionality or 'in the now' also helped men re-establish a sense of security from future threats.

'It just heightens that sense of we're not here forever. So I think it's helped give us that sense of actually this needs to happen, let's make it happen.. so I think it gives us just a bit more sense of urgency' (P19, T1, 39 yrs, Married, Surgery)

Some admitted occasional fears of recurrence, although these fears were often not felt to be severe or enduring ('it's not an ever present feeling' P13, T2, 27 yrs, In a relationship, Surgery). Although some single men discussed the possibility of future relationships being affected, these concerns were quickly relinquished ('I don't think it's gonna be a 
problem, certainly not with my confidence' P2, T1, 24 yrs, Single, Surgery). Conversely, in one participant, ongoing struggles to tolerate uncertainty and let go of the lifethreatening nature of cancer led to feelings of sadness and fear at Time 2 ('I wouldn't say I'm back to total normal, no, not quite, I still don't feel right' P10, T2, 41 yrs, Married, Surgery). Negative adjustment was also characterised by feeling more susceptible to future cancers, both other cancer types and bilateral testicular cancer, and other health risks ('wait for the next thing to give up' P10, T2, 41 yrs, Married, Surgery).

Overall, holding onto the anchors of security was also important alongside letting go of the threats. For many men, access to the Clinical Nurse Specialist was highly valued, especially the security gained from knowing that they were available via telephone. In addition, due to the threat of treatment to future fatherhood, men held on to the sense of security gained from banking their sperm or from already being a father, with some expressing concerns over the financial implications of Assistive Reproductive Techniques. Single men expressed confidence in their body's ability to recover and let go of their concerns as something to be dealt with in the future. One participant reframed the threat to fertility as an advantage, giving him greater control in determining his future and mother of his children and potentially sparing him from being forced into premature fatherhood.

'I've got the power to pick who I want my girlfriend to be, and I've got the power to pick who I want the mother of my child to be, so I'm one-nil up as far as I'm concerned' (P20, T1, 22 yrs, Single, Surgery+C**)

The threat to fertility magnified the significance of cancer as biographically disruptive in those who wanted children in the near future, with some struggling at Time 2 if they dwelt on these fears and allowed resentment towards cancer to preside, rather than accept the need to 'wait and see'. 
'Just the resentment, you can't be as you were... that one's a bit more of a difficult one to get over, lots of our friends are obviously having babies... which is something that we feel that we're more than prepared to do... so I know that I'll never be able to look back on the cancer and think oh well that was a bit tough but I'm so glad it happened, there's always going be a bit of hatred, bit of resentment there' (P14, T2, 31 yrs, Married, Surgey $+\mathrm{C}^{*}$ )

\section{Discussion}

The grounded theory presented in this paper explains how men can often positively adjust to the threats posed by testicular cancer relatively quickly. It also highlights the processes leading to a positive or negative adjustment trajectory during early survivorship. The processes explain how most testicular cancer survivors in our study were able to emerge with their identity undisrupted, gain a sense of normality, acceptance, coherence, perspective and security in their relationships; and derive positive meaning, which were key dimensions of positive adjustment. These processes dismantled threats to the body, masculinity, identity, health and future, regardless of men's prognosis or treatment received. Men treated more intensively drew more actively on these strategies, in light of having greater disruption to their lives. Our finding that men felt they had returned to normality relatively quickly, helps to explain previous quantitative findings that show few or no differences between long-term testicular cancer survivors and healthy men [40, 12, 13, 41]. It also extends Brennan's [42] conceptualisation of adjustment as a dynamic process, involving both positive and negative transitions, by providing a more specific account of adjustment relevant to younger survivors of testicular cancer.

Our research also highlights the process of negative adjustment over time. Firstly, instead of holding onto their anchors of security (relationships, fatherhood status, work and 
confidence in physician) and attempting to relinquish fears, men who held onto the threats of testicular cancer and ruminated on them, reported increasing distress. Previous work by Jones and Payne [11] proposed that having fewer 'safety signals' (i.e. hospital appointments, contact with patients) led to poorer outcomes. Our study builds on this, although highlights that men's ability to hold on to their anchors of security and let go of the threats was more important in adjustment. It is also probable that negative adjustment may reflect personality traits of neuroticism or rumination that have been associated with distress $[43,44]$. Therefore, we suggest that interventions that promote acceptance and the ability to relinquish fears, as well as live 'in the present', would be helpful for men. This finding fits well with mindfulness-based interventions that encourage selfmanagement strategies and have shown promising results in cancer patients $[45,46]$. Interventions by health professionals to educate men on how to manage their fears may also be appropriate for male survivors [47]. Positive reframing of threats was also a key strategy that could be incorporated into interventions. To date, very few interventions have been developed for this population, so findings from our research adds to this knowledge base $[48,49,8]$.

Illness perceptions of cancer, shown to be an important factor in adjustment in the wider literature, were important in explaining how men were able to reframe the illness in positive terms or continue to perceive it as a threat [50,51]. For instance, perceptions of testicular cancer as an acute and curable illness of relatively minor significance are in line with the main tenets of this existing theory [50]. In our research, perceptions of testicular cancer as either a specific cancer (positive adjustment) or as a generalised disease (negative adjustment) were also important. For instance, the latter meant that prior assumptions and connotations towards cancer as a life-threatening disease endured, so perceptions of the threat to the future were not dismantled. Whereas, perceiving the 
disease as a specific cancer meant the threat was contained. As part of this process, resolving the discrepancy between men's assumptions and the actual experience was important in promoting a sense of illness coherence $[39,52]$ as opposed to ambivalence, illustrating the power of cultural and societal connotations towards cancer. Further investigation of illness perceptions in this population is warranted, especially whether this prior theory could be expanded to include cancer specificity or distinctiveness (vs. generalised) perceptions. This may be useful as illness perceptions are modifiable variables that could be targeted by future interventions, such as patient education and public awareness programmes [53].

Furthermore, while an active approach to eliciting support helped men adjust positively, men who had ongoing concerns and continued with a stoical and silent approach seemed to worsen over time. Similar findings on coping and masculinities have been reported elsewhere $[54,55]$. Stoicism was influenced by a more ridged adherence to hegemonic views of masculinity and the desire to maintain a positive front, culminating in feelings of abandonment from health professionals and isolation from others. A testicular cancer specific patient concerns inventory (PCI) could be useful for eliciting concerns from such men [56] as could a holistic needs assessment, as suggested by the NCSI [57]. These findings have implications for follow-up, which is currently focused on detecting recurrences, and previous work has also highlighted that greater improvement in psychosocial support is needed during follow-up [58, 59]. One-on-one peer support could also be valuable for these men, as it is for survivors of other cancers [60]. E-health interventions including online peer support may be particularly useful for male survivors, as they minimise the stigma of help-seeking [61].

In this study, men who had not yet achieved key 'milestones' of masculinity, more actively sought to re-establish security and control through strategies, such as enhancing 
the self. This echoes cognitive adaptation theory [62], and our study has also found that accepting the need to 'wait and see' over fertility was also important in adjustment. Men who imminently wanted children could struggle at times, highlighting the need for support for these men and their spouses. Deriving a sense of meaning from cancer and a sense of coherence was particularly important, especially for these men [63].

Contrary to previous research on men with cancer [64], testicular cancer did not disrupt men's sense of identity [65] in almost all cases, as men engaged in the process of preserving and enhancing the normal self through their work roles or fitness regimes and defended against illness centrality [66]. High levels of illness centrality were found elsewhere to be associated with poorer adjustment, which supports our findings [67]. It is notable that men quickly accepted and normalised the loss of a testicle, often using humour over the issue, with any body image issues largely transient, contrary to some previous qualitative literature [25,30] although similar to findings in another study [9]. Limitations of the study include the low number of men who were negatively adjusted, which may reflect reluctance on the part of such men to participate. Therefore, it is possible that men in the study may be a self-selecting sample. There was also no data on the characteristics of non-responders. The sample also lacked diversity with regards to demographics characteristics, and the findings may not be applicable to cancer survivors with poor prognostic outcomes. The role of a female interviewer may have influenced the findings, particularly as sexual function was rarely mentioned, as this topic may threaten men's identities. When this topic was raised by participants, this was always to assert that their sexual functioning had been unaffected. Review evidence shows contradictory findings regarding the levels of sexual dysfunction evident in testicular cancer survivors as there is a wide variation across studies [17]. It is, therefore, unknown whether discussion of sexual functioning would have impacted on the overall Grounded Theory 
developed; however it is unlikely that inclusion of this topic would have altered the main conceptual processes in our theory.

While the longitudinal design was initially intended to assess change over time, few changes were evident as most participants continued on a positive adjustment trajectory. The six month gap between interviews, influenced partly by time constraints of the study, did not therefore capture much change; however the Time 2 interview data added greater richness to the findings and further supports the grounded theory developed. Although it is possible that the findings may have differed had the time interval between interviews been longer, we think this is unlikely given the positive adjustment trajectory observed.

\section{Conclusions}

Our study contributes to the limited knowledge regarding the psychosocial impact on younger testicular cancer survivors and provides an insight into the processes through which men positively adjust. It has implications for the assessment and management of care for men treated for testicular cancer, especially those struggling to adjust. For example, health professional interventions could include supporting positive illness beliefs, enabling discussion of negative perceptions, managing long-term side effects, assessing men's support networks, encouraging men to reveal their concerns, providing fertility advice, helping men accept and normalise body image issues, and facilitating peer support. Interventions that preserve men's independence are also needed, including

informal 'support', particularly one-on-one peer mentoring. Implementation of interventions that are additional to current standard best practice should be evaluated in a larger study.

Acknowledgements: We would like to thank all of the nurses and oncologists who assisted with recruiting patients into the study, and all of the men who gave their time to 
be interviewed. This project was a $\mathrm{PhD}$ funded studentship by Oxford Brookes

University.

No conflicts of interest

\section{References}

1. Shanmugalingam T, Soultati A, Chowdhury S, Rudman S, Van Hemelrijck M. Global incidence and outcome of testicular cancer. Clin Epidemiol. 2013;5:417.

2. Cancer Research UK. Testicular cancer - UK incidence statistics. 2015.

http://info.cancerresearchuk.org/cancerstats/types/testis/incidence/uk-testicular-cancerincidence-statistics. Accessed 8th January 2015.

3. Le Cornet C, Lortet-Tieulent J, Forman D, Béranger R, Flechon A, Fervers B et al. Testicular cancer incidence to rise by $25 \%$ by 2025 in Europe? Model-based predictions in 40 countries using population-based registry data. Eur J Cancer. 2014;50(4):831-9.

4. Quaresma M, Coleman MP, Rachet B. 40-year trends in an index of survival for all cancers combined and survival adjusted for age and sex for each cancer in England and Wales, 1971-2011: a population-based study. Lancet. 2014(0). doi:http://dx.doi.org/10.1016/S0140-6736(14)61396-9.

5. Beyer J, Albers P, Altena R, Aparicio J, Bokemeyer C, Busch J et al. Maintaining success, reducing treatment burden, focusing on survivorship: highlights from the third European consensus conference on diagnosis and treatment of germ-cell cancer. Ann Oncol. 2013;24(4):878-88.

6. Fleer J, Hoekstra HJ, Sleijfer DT, Hoekstra-Weebers JE. Quality of life of survivors of testicular germ cell cancer: a review of the literature. Support Care Cancer.

2004;12(7):476-86.

7. Luckett T, Butow PN, King MT, Olver IN. Psycho-social issues in long-term survivors of testicular cancer: Directions for future research. Asia Pac J Clin Oncol. 2008;4(3):12531. doi:10.1111/j.1743-7563.2008.00181.x.

8. Moynihan C, Bliss JM, Davidson J, Burchell L, Horwich A. Evaluation of adjuvant psychological therapy in patients with testicular cancer: randomised controlled trial. BMJ. 1998;316(7129):429-35.

9. Chapple A, McPherson A. The decision to have a prosthesis: A qualitative study of men with testicular cancer. Psychooncology. 2004;13(9):654-64.

10. Brand S, Williams H, Braybrooke J. How has early testicular cancer affected your life? A study of sexual function in men attending active surveillance for stage one testicular cancer. Eur J Oncol Nurs. 2014. doi:10.1016/j.ejon.2014.11.001.

11. Jones GY, Payne S. Searching for safety signals: the experience of medical surveillance amongst men with testicular teratomas. Psychooncology. 2000;9(5):385-94. 12. Joly F, Héron JF, Kalusinski L, Bottet P, Brune D, Allouache N et al. Quality of Life in Long-Term Survivors of Testicular Cancer: A Population-Based Case-Control Study. J Clin Oncol 2002;20(1):73-80. doi:10.1200/jco.20.1.73.

13. Fleer J, Hoekstra H, Sleijfer D, Tuinman M, Klip E, Hoekstra-Weebers J. Quality of life of testicular cancer survivors and the relationship with sociodemographics, cancerrelated variables, and life events. Support Care Cancer. 2006;14(3):251-9. doi:10.1007/s00520-005-0879-3. 
14. Rudberg L, Nilsson S, Wikblad K. Health-related quality of life in survivors of testicular cancer 3 to 13 years after treatment. J Psychosoc Oncol. 2000;18(3):19-31. doi:10.1300/J077v18n03 02.

15. Hoyt M, Cano S, Saigal C, Stanton A. Health-related quality of life in young men with testicular cancer: validation of the Cancer Assessment for Young Adults (CAYA). J Cancer Surviv. 2013;7(4):630-40. doi:10.1007/s11764-013-0302-x.

16. Holzner B, Efficace F, Basso U, Johnson CD, Aaronson NK, Arraras JI et al. Crosscultural development of an EORTC questionnaire to assess health-related quality of life in patients with testicular cancer: The EORTC QLQ-TC26. Qual Life Res.

2013;22(2):369-78. doi:10.1007/s11136-012-0147-1.

17. Jonker-Pool G, Van de Wiel H, Hoekstra H, Sleijfer D, Van Driel M, Van Basten J et al. Sexual Functioning After Treatment for Testicular Cancer-Review and MetaAnalysis of 36 Empirical Studies Between 1975-2000. Arch Sex Behav. 2001;30(1):5574. doi:10.1023/a:1026468707362.

18. Dahl AA, Bremnes R, Dahl O, Klepp O, Wist E, Fosså SD. Is the Sexual Function Compromised in Long-Term Testicular Cancer Survivors? Eur Urol. 2007;52(5):143847. doi:http://dx.doi.org/10.1016/j.eururo.2007.02.046.

19. Dahl AA, Haaland CF, Mykletun A, Bremnes R, Dahl O, Klepp O et al. Study of Anxiety Disorder and Depression in Long-Term Survivors of Testicular Cancer. J Clin Oncol. 2005;23(10):2389-95. doi:10.1200/jco.2005.05.061.

20. Rossen P, Pedersen AF, Zachariae R, von der Maase H. Sexuality and body image in long-term survivors of testicular cancer. Eur J Cancer. 2012;48(4):571-8.

21. Keegan T, Lichtensztajn D, Kato I, Kent E, Wu X-C, West M et al. Unmet adolescent and young adult cancer survivors information and service needs: a population-based cancer registry study. J Cancer Surviv. 2012;6(3):239-50. doi:10.1007/s11764-012-02199.

22. Smith AB, King M, Butow P, Luckett T, Grimison P, Toner GC et al. The prevalence and correlates of supportive care needs in testicular cancer survivors: a cross-sectional study. Psychooncology. 2013;3(10).

23. Bender JL, Wiljer D, To MJ, Bedard PL, Chung P, Jewett MA et al. Testicular cancer survivors' supportive care needs and use of online support: a cross-sectional survey.

Support Care Cancer. 2012;20(11):2737-46.

24. Alanee S, Russo P. Suicide in men with testis cancer. Eur J Cancer Care 2012;21(3).

25. Kristjanson L, Ng C, Oldham L, Wilkes L, White K, Maher L. The impact and responses of men who have experienced testicular cancer. The Australian Journal of Cancer Nursing 2006;7(1):10-7.

26. Brodsky MS. The Young Male Experience with Treatment for Nonseminomatous Testicular Cancer. Sex Disabil. 1999;17(1):65-77. doi:10.1023/a:1021455813897.

27. Carpentier MY, Fortenberry JD. Romantic and Sexual Relationships, Body Image, and Fertility in Adolescent and Young Adult Testicular Cancer Survivors: A Review of the Literature. J Adolesc Health. 2010;47(2):115-25.

doi:10.1016/j.jadohealth.2010.04.005.

28. Jefford M, Karahalios E, Pollard A, Baravelli C, Carey M, Franklin J et al.

Survivorship issues following treatment completion-results from focus groups with Australian cancer survivors and health professionals. J Cancer Surviv 2008;2(1):20-32. doi:10.1007/s11764-008-0043-4.

29. Carpentier MY, Fortenberry JD, Ott MA, Brames MJ, Einhorn LH. Perceptions of masculinity and self-image in adolescent and young adult testicular cancer survivors: implications for romantic and sexual relationships. Psychooncology. 2011;20(7):738-45. doi:10.1002/pon.1772. 
30. Gurevich M, Bishop S, Bower J, Malka M, Nyhof-Young J. (Dis)embodying gender and sexuality in testicular cancer. Soc Sci Med. 2004;58(9):1597-607.

doi:10.1016/s0277-9536(03)00371-x.

31. Seymour-Smith S. A reconsideration of the gendered mechanisms of support in online interactions about testicular implants: A discursive approach. Health Psychol 2013;32(1):91-9. doi:10.1037/a0029507.

32. Chapple A, Ziebland S. The role of humor for men with testicular cancer. Qual Health Res. 2004;14(8):1123-39.

33. Department of Health, MacmillanCancer Support, NHS Improvement. Living with \& Beyond Cancer: Taking Action to Improve Outcomes (an update to the 2010 The National Cancer Survivorship Initiative Vision)2013.

34. Calman L, Brunton L, Molassiotis A. Developing longitudinal qualitative designs: lessons learned and recommendations for health services research. BMC Med Res Methodol. 2013;13(1):14.

35. Adolescent and Young Adult Oncology Progress Review Group, National Cancer Institute, LIVESTRONG Young Adult Alliance. Closing the Gap: Research and Care Imperatives for Adolescents and Young Adults with Cancer. 2006.

36. Charmaz K. Constructing grounded theory: a practical guide through qualitative analysis. Sage Publications; 2006.

37. Dey I. Grounding Grounded Theory: Guidelines for Qualitative Inquiry. Academic Press; 1999.

38. Mays N, Pope C. Qualitative research in health care - Assessing quality in qualitative research. BMJ. 2000;320:50-2.

39. Moss-Morris R, Weinman J, Petrie K, Horne R, Cameron L, Buick D. The revised illness perception questionnaire (IPQ-R). Psychol health. 2002;17(1):1-16.

40. Fossa SD, Oldenburg J, Dahl AA. Short- and long-term morbidity after treatment for testicular cancer. BJU Int. 2009;104(9 Pt B):1418-22.

41. Mykletun A, Dahl AA, Haaland CF, Bremnes R, Dahl O, Klepp O et al. Side effects and cancer-related stress determine quality of life in long-term survivors of testicular cancer. J Clin Oncol. 2005;23(13):3061-8.

42. Brennan J. Adjustment to cancer-coping or personal transition? Psychooncology. 2001;10(1):1-18.

43. Soo H, Sherman KA. Rumination, psychological distress and post-traumatic growth in women diagnosed with breast cancer. Psychooncology. 2015;24(1):70-9. doi:10.1002/pon.3596.

44. Grov E, Fossa S, Bremnes R, Dahl O, Klepp O, Wist E et al. The personality trait of neuroticism is strongly associated with long-term morbidity in testicular cancer survivors. Acta Oncol. 2009;48(6):842-9.

45. Piet J, Würtzen H, Zachariae R. The effect of mindfulness-based therapy on symptoms of anxiety and depression in adult cancer patients and survivors: A systematic review and meta-analysis. J Consult Clin Psychol. 2012;80(6):1007.

46. Shennan C, Payne S, Fenlon D. What is the evidence for the use of mindfulness-based interventions in cancer care? A review. Psychooncology. 2011;20(7):681-97.

doi:10.1002/pon.1819.

47. Chambers SK, Ferguson M, Gardiner RA, Aitken J, Occhipinti S. Intervening to improve psychological outcomes for men with prostate cancer. Psychooncology. 2012;22(5):1025-34. doi:10.1002/pon.3095.

48. Martin F, Turner A, Bourne C, Batehup L. Development and qualitative evaluation of a self-management workshop for testicular cancer survivor-initiated follow-up. Oncol Nurs Forum. 2013;40(1):E14-E23. 
49. Pauley PM, Morman MT, Floyd K. Expressive writing improves subjective health among testicular cancer survivors: A pilot study. Int J Mens Health. 2011;10(3):199-219. doi:10.3149/jmh.1003.199.

50. Leventhal H, Nerenz D, Steele D. Illness representations and coping with health threats. In: Baum A TS, Singer JE,, editor. Handbook of psychology and health. Hillsdale, New Jersey: Erlbaum; 1984. p. 219-52.

51. Traeger L, Penedo FJ, Gonzalez JS, Dahn JR, Lechner SC, Schneiderman N et al. Illness perceptions and emotional well-being in men treated for localized prostate cancer. J Psychosom Res. 2009;67(5):389-97.

52. Antonovsky A. Unraveling the mystery of health : how people manage stress and stay well. Jossey-Bass social and behavioral science series San Francisco Hossey-Bass; 1987. 53. Ashley L, Marti J, Jones H, Velikova G, Wright P, editors. Illness Perceptions Within 6 Months of Cancer Diagnosis Are an Independent Prospective Predictor of Future Health-Related Quality of Life (HRQoL) 15 Months Post-Diagnosis. International Psycho Oncology Society 2014; Lisbon, Portugal: Psycho Oncology.

54. Landívar EG. Concepts, theories and psychosocial factors in cancer adaptation. Actas Esp Psiquiatr. 2005;33(6):390-7.

55. Evans J, Frank B, Oliffe JL, Gregory D. Health, Illness, Men and Masculinities (HIMM): a theoretical framework for understanding men and their health. J Mens Health. 2011;8(1):7-15.

56. Rogers SN, El-Sheikha J, Lowe D. The development of a Patients Concerns Inventory (PCI) to help reveal patients concerns in the head and neck clinic. Oral Oncology. 2008;45(7):555-61. doi:10.1016/j.oraloncology.2008.09.004.

57. Department of Health, Macmillan Cancer Support, NHS Improvement. The National Cancer Survivorship Initiative Vision 2010.

58. Jefford M, Rowland J, Grunfeld E, Richards M, Maher J, Glaser A. Implementing improved post-treatment care for cancer survivors in England, with reflections from Australia, Canada and the USA. Br J Cancer. 2013;108(1):14-20. doi:10.1038/bjc.2012.554.

59. Lewis RA, Neal RD, Hendry M, France B, Williams NH, Russell D et al. Patients' and healthcare professionals' views of cancer follow-up: systematic review. Br J Gen Pract. 2009;59(564):248-59. doi:10.3399/bjgp09X453576.

60. Meyer A, Coroiu A, Korner A. One-to-one peer support in cancer care: a review of scholarship published between 2007 and 2014. Eur J Cancer Care 2015.

61. Wootten AC, Abbott J-AM, Meyer D, Chisholm K, Austin DW, Klein B et al. Preliminary Results of a Randomised Controlled Trial of an Online Psychological Intervention to Reduce Distress in Men Treated for Localised Prostate Cancer. Eur Urol. 2014(0). doi:http://dx.doi.org/10.1016/j.eururo.2014.10.024.

62. Taylor SE. Adjustment to threatening events: A theory of cognitive adaptation.

American psychologist. 1983;38(11):1161.

63. Allart P, Soubeyran P, Cousson-Gélie F. Are psychosocial factors associated with quality of life in patients with haematological cancer? A critical review of the literature. Psychooncology. 2013;22(2):241-9.

64. Wenger LM. 'Living under assault': Men making sense of cancer. Eur J Cancer Care. 2013;22(3):389-99. doi:10.1111/ecc.12042.

65. Bury M. Chronic illness as biographical disruption. Sociol Health Illn. 1982;4(2):16782.

66. Helgeson VS, Novak SA. Illness centrality and well-being among male and female early adolescents with diabetes. J Pediatr Psychol. 2007;32(3):260-72.

67. Park CL, Bharadwaj AK, Blank TO. Illness centrality, disclosure, and well-being in younger and middle-aged adult cancer survivors. Br J Health Psychol. 2011;16:880-9. 
Table 1: Summary of participants' demographic and treatment information

\begin{tabular}{ll}
\hline $\begin{array}{l}\text { Participant Demographics } \\
\text { (Time 1) }\end{array}$ & N (\%) \\
\hline Age (years) & \\
$20-24$ & $2(11)$ \\
$25-29$ & $3(17)$ \\
$30-34$ & $4(22)$ \\
$35-39$ & $4(22)$ \\
$40-45$ & $5(28)$
\end{tabular}

\section{Highest Educational}

\section{Qualification}

GCSE's or equivalent $^{\text {a }} \quad 6(33)$

A-Level's or equivalent ${ }^{\mathrm{b}} \quad 1$ (6)

Bachelor University Degree $\quad 9(50)$

Postgraduate Qualification 2(11)

\section{Employment}

Full-time $12(67)$

Part-time $4(22)$

Unemployed 2(11)

Marital status

Married $9(50)$

In a relationship/Cohabiting $\quad 4(22)$

Single $\quad 5(28)$

\section{Ethnicity}

White British 17 (94)

Asian British 1 (6)

\section{Living Arrangements}

Live with partner/children 13 (72)

Live with parents 3 (17)

Live alone 2 (11)

Initial Treatment $^{\mathrm{c}}$

Surgery alone $6(33)$ 
Surgery + Chemotherapy/or

$12(67)$

\section{radiotherapy}

a: Exams which are usually taken at the age of 16 in the UK

b: Exams which are usually taken at the age of 18 in the UK

c: At Time 1 interview

\section{Box 1- Abbreviations}

T1 - Time 1 Interview

T2 - Time 2 Interview

Surgery - Treated with surgery alone

Surgery $+C / R-$ Treated with surgery and

chemotherapy/radiotherapy

* -Treated for a recurrence

**- Treated for advanced disease 


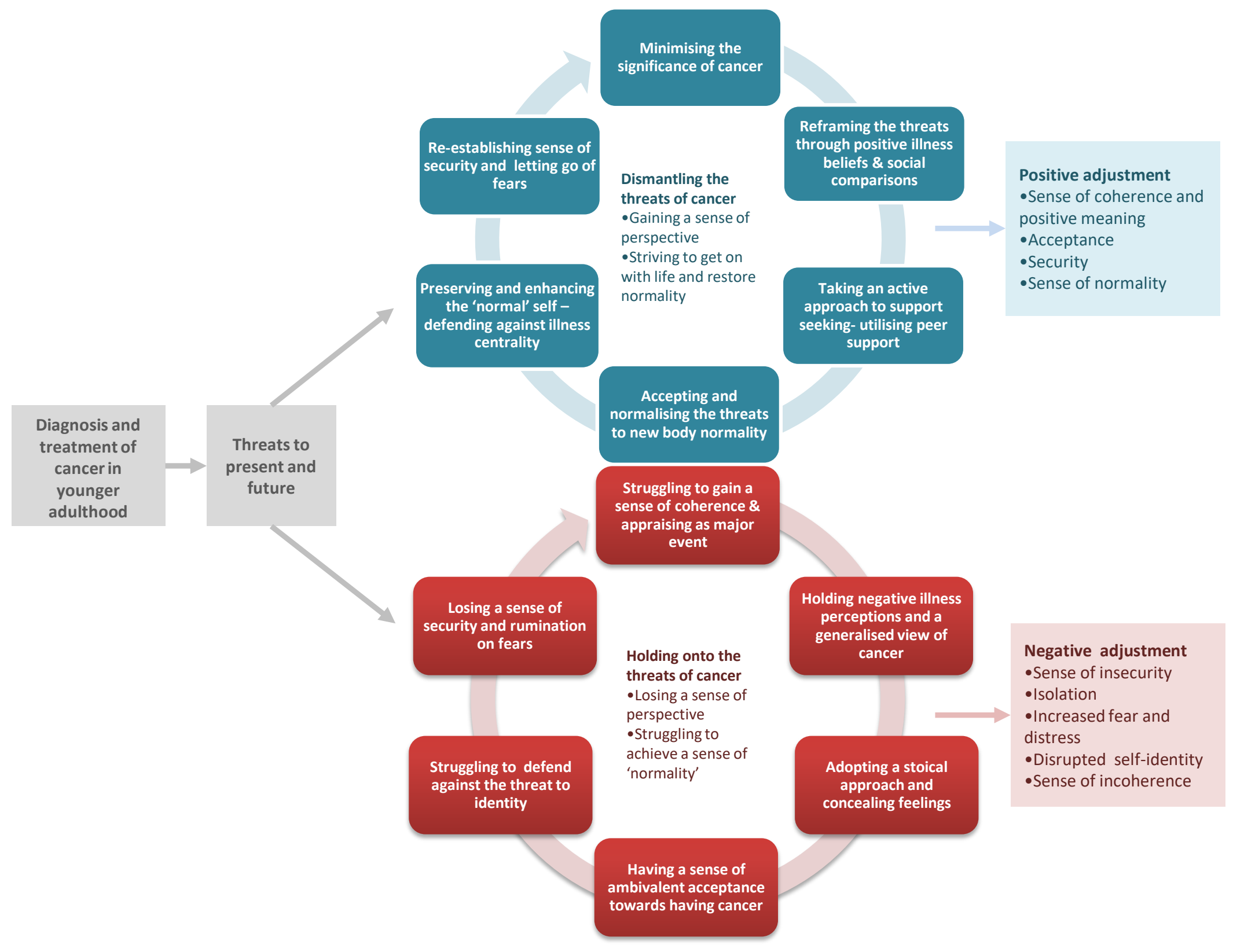

